\title{
Skeletal muscle substrate metabolism during exercise: methodological considerations
}

\author{
Gerrit van Hall, José González-Alonso, Massimo Sacchetti and Bengt Saltin* \\ The Copenhagen Muscle Research Centre, Rigshospitalet, section 7652, Tagensvej 20, DK-2200 Copenhagen N, Denmark
}

\begin{abstract}
The aim of the present article is to evaluate critically the various methods employed in studies designed to quantify precisely skeletal muscle substrate utilization during exercise. In general, the pattern of substrate utilization during exercise can be described well from $\mathrm{O}_{2}$ uptake measurements and the respiratory exchange ratio. However, if the aim is to quantify limb or muscle metabolism, invasive measurements have to be carried out, such as the determination of blood flow, arterio-venous (a-v) difference measurements for $\mathrm{O}_{2}$ and relevant substrates, and biopsies of the active muscle. As many substrates and metabolites may be both taken up and released by muscle at rest and during exercise, isotopes can be used to determine uptake and/or release and also fractional uptake can be accounted for. Furthermore, the use of isotopes opens up further possibilities for the estimation of oxidation rates of various substrates. There are several methodological concerns to be aware of when studying the metabolic response to exercise in human subjects. These concerns include: (1) the muscle mass involved in the exercise is largely unknown (bicycle or treadmill). Moreover, whether the muscle sample obtained from a limb muscle and the substrate and metabolite concentrations are representative can be a problem; (2) the placement of the venous catheter can be critical, and it should be secured so that the blood sample represents blood from the active muscle with a minimum of contamination from other muscles and tissues; (3) the use of net limb glycerol release to estimate lipolysis is probably not valid (triacylglycerol utilization by muscle), since glycerol can be metabolized in skeletal muscle; (4) the precision of blood-borne substrate concentrations during exercise measured by a-v difference is hampered since they become very small due to the high blood flow. Recommendations are given in order to obtain more quantitative and conclusive data in studies investigating the regulatory mechanisms for substrate choice by muscle.
\end{abstract}

\section{Free fatty acids: Triacylglycerols: Exercise: Metabolic rate: Respiratory exchange ratio}

Through the years, many approaches have been used to evaluate the contribution of carbohydrate and lipids to the increased energy requirements of skeletal muscle during exercise. Since both substrates are stored in the human body outside as well as within the muscle, another question is to what extent the intra- and extra-muscular substrate sources are utilized as a function of exercise intensity, work duration and substrate availability.

Determination of the respiratory exchange ratio (RER) from the gas exchange in the lungs or the RQ from the arterial and venous concentration of blood gases can give quite a precise value for the relative contribution of carbohydrates and lipids at the whole-body level or over a limb. To determine the utilization of blood-borne substrates, i.e. the contribution of extramuscular sources, arterio-venous (a-v) differences for relevant substrates and metabolites have to be determined. Using the Fick principle, the net uptake or release of, for example, glucose, fatty acids (FA) glycerol, triacylglycerols (TG; as VLDL-TG or serum total TG) and lactate is obtained. These measurements can be performed, despite the fact that $a-v$ differences may be small when the blood flow is high during exercise. However, these measurements do not indicate whether the substrates have been metabolized for an energy yield or have been stored in the muscle. The inclusion of isotopes in these experiments (radioactive or stable) can add more information on the fate of the substrates in muscle.

\footnotetext{
Abbreviations: a-v, Arterio-venous; $\mathrm{CHO}$, carbohydrates; FA, fatty acids; FFA, free fatty acids; RER, respiratory exchange ratio; TG, triacylglycerols; $V_{\mathrm{O}_{2}}$, $\mathrm{O}_{2}$ uptake.
}

*Corresponding author: Dr Bengt Saltin, fax +45 3545 7634, email cmrc@rh.dk 
The most common approach to determining the utilization of muscle glycogen and the TG stored in the muscle has been to obtain muscle tissue with a biopsy technique before and after exercise and to use biochemical analysis to measure the concentration. More recently, magnetic resonance spectroscopy (proton or ${ }^{13} \mathrm{C}$ ) has come into use (for a discussion of the advantages and disadvantages of these techniques, see Boesch, 1999; Price et al. 1999). In a few studies electron microscopy has been used to estimate changes in a non-quantitative manner of both the number of glycogen granules (Sjöström et al. 1982; Fridén et al. 1989) and of the size of lipid droplets (Oberholzer et al. 1976; Staron et al. 1989). To answer the question as to the relative contribution of extramuscular $v$. intramuscular substrate sources for energy, in addition to the previously mentioned measurements, the amount of muscle mass engaged in the exercise has to be known, since the concentrations of substrates and metabolites in the muscle are expressed per $\mathrm{kg}$ muscle tissue. Although imaging techniques are now available to quantify the muscle mass performing the work, this problem is still in part unsolved, as will be discussed later.

The topic of energy metabolism has a long history, with its basis outlined by Lavoisier (1777), followed by Atwater \& Benedict (1902) and Benedict \& Carpenter (1910), to mention some of the early pioneers who provided the basis for indirect calorimetry, the energy value of various substrates and functional efficiency estimations. Exercise-related studies became common in the latter part of the 19th century, followed by very detailed studies in the first decades of this century by Zuntz (1901) and Krogh \& Lindhard (1920). Indeed, by the end of the 1930s the principal features of exercise metabolism were established (Christensen, 1932; Dill et al. 1932; Bang, 1936; Böje, 1936). In the 1950-60s measurements of a-v difference and radioactive isotopes came into use (Zierler, 1961; Havel et al. 1964, 1967). During this period the taking of muscle biopsies had a renaissance when Bergström (1962) reintroduced the needle originally described by Duchenne in the middle of the 19th century. Most of the more general biochemically-oriented early work is summarized in Machina Carnis (Needham, 1971) and exercise-related studies are described in Muscle Metabolism During Exercise (Pernow \& Saltin, 1971). Since then, numerous books and reviews have dealt with this subject, including Exercise Nutrition and Energy Metabolism (Horton \& Terjung, 1988), Exercise Metabolism (Hargreaves, 1995), and most recently, Skeletal Muscle Metabolism in Exercise and Diabetes (Richter et al. 1998).

In the present article methodological considerations related to indirect calorimetry, a-v difference (blood flow) and muscle biopsies (glycogen, TG) will be emphasized as they relate to cycle ergometry and the knee-extensor exercise (Fig. 1) models. Since data from some relevant investigations will be used as examples to demonstrate the difficulty in quantifying precisely substrate choice, the topic of substrate metabolism will be covered in part. However, the account will be descriptive rather than regulatory or mechanistic.

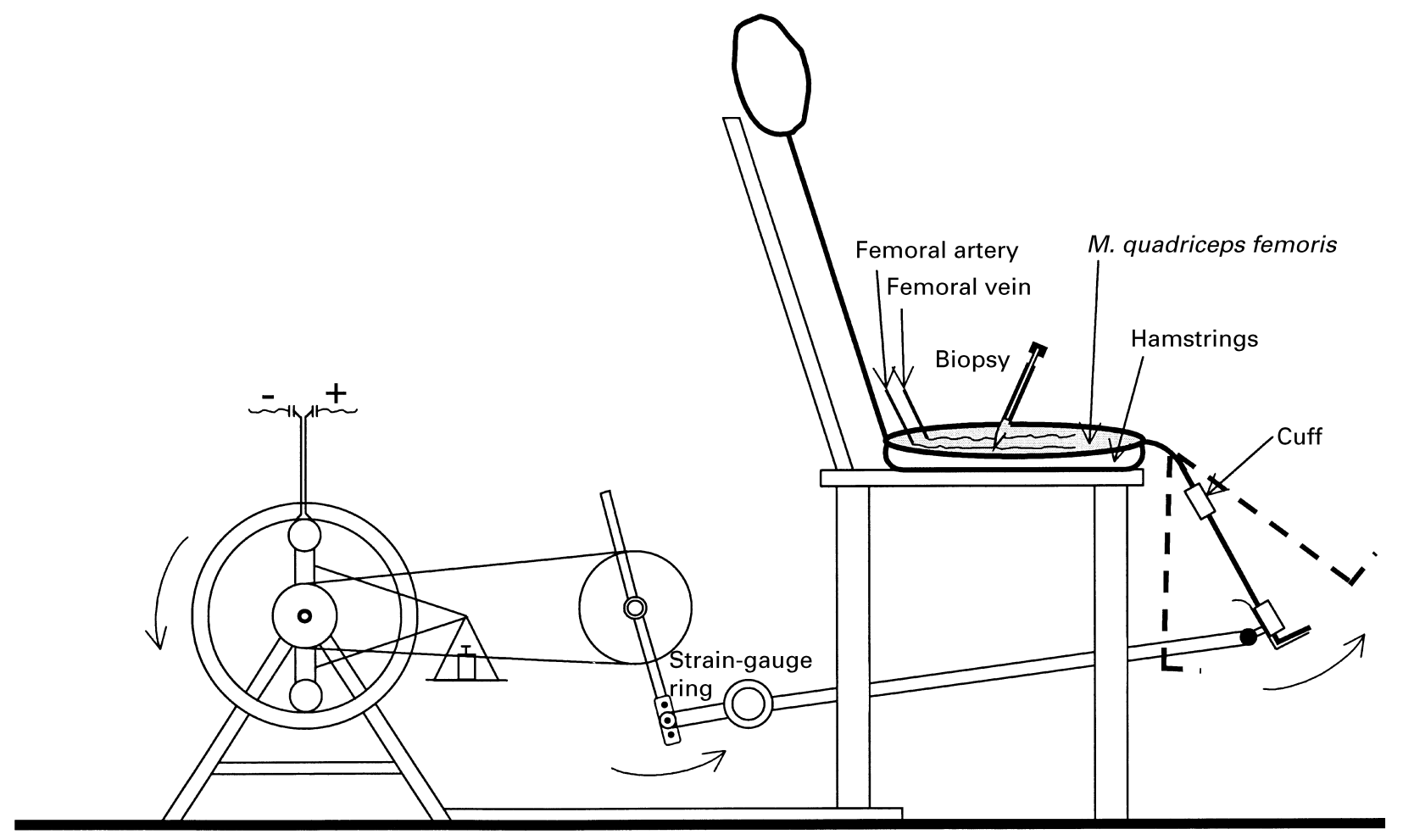

Fig. 1. The knee-extension exercise model. Straps are used around the trunk and hip to minimize upper body movement and stabilizing the torso. In addition a cuff is placed just distal to the knee, which when inflated blocks the blood flow from the lower part of the leg. A rod connects the subject's ankle to the crank of the Krogh cycle ergometer. By contraction of the knee-extensor, work is produced. Fly wheel momentum and gravity permit the return of the lower part of the leg to its vertical position without the hamstrings being active. 


\section{Methodological considerations \\ Blood flow and limb oxygen uptake}

There are now several good blood-flow methods that can be applied during exercise (see Rådegran, 1999). In general, either the arterial inflow (femoral artery) or the venous outflow (femoral vein) is measured. When comparing the two measurements there is a good agreement over the full range of blood flows (Kim et al. 1995; Rådegran, 1997). Although this is the case, there may be a small additional arterial inflow to the peripheral parts of the leg (e.g. obturator artery) other than via the femoral artery. As the magnitude of the measured femoral artery inflow is the same as that measured in the femoral vein, not all the arterial inflow to the leg is drained by the femoral vein (e.g. three to four small veins in the lateral and posterior parts of the hip region). When a dye (cardio-green) is injected into the femoral artery, not all the cardio-green is retrieved in the femoral vein when blood is sampled just distal to the inguinal ligament. The more proximally the arterial catheter is placed in the femoral artery, the lower the percentage recovery. When catheter placement is optimal (approximately at the level of the inguinal ligament), up to $90 \%$ of the dye can be found in the femoral vein during light-tointense exercise. Based on the anatomy with regard to both vessels in the lower limb and muscles involved in the exercise, it is easy to envisage that there should not be a complete match between the two vessels (Fig. 2). This is not a critical issue. What is of importance is that the sampled blood in the vein represents the capillary blood of active muscles.

One obvious concern in this respect relates to the fact that blood is usually sampled in the femoral vein proximal to the merger with the saphenous vein. The contamination of the blood flow in the saphenous vein primarily from the skin is, however, not very large. Measurements of femoral venous blood flow proximal (anterograde) and distal (retrograde) to the origin of the saphenous vein reveal only slightly higher blood flows in the proximal position (Fig. 3 and Table 1). The largest $(0 \cdot 3-0 \cdot 4$ litre/min) difference is observed when skin temperature is high (Savard et al. 1988). This finding was confirmed by direct measurements of the blood flow in the saphenous vein in one subject during moderate and intense cycle exercise in a warm $\left(40^{\circ}\right)$ and a cold $\left(17^{\circ}\right)$ environment. In the warm environment, saphenous blood flow varied between 0.35 and 0.46 litre/min, whereas blood flow was only $0 \cdot 06-0.08$ litre/min in the cold environment. Thus, in a warm environment contamination by skin blood flow can be a problem, not only at rest, but also during exercise. In a neutral environment, saphenous blood flow constitutes only a very small proportion of the blood flow measured in the femoral vein at the level of the inguinal ligament (approximately 1-5\%) and its functional significance is minor (Table 2). This is important and explains why $\mathrm{O}_{2}$ saturation and tension in the femoral vein are similarly low when measured proximally and distally, as $\mathrm{O}_{2}$ saturation in the saphenous vein is as high as approximately $90 \%$, when exercising in the heat, and between 60 and $75 \%$ when exercising in the cold or in a neutral environment (Fig. 4(a)). In addition, there could be some small differences in $\mathrm{O}_{2}$ saturation and pressure in different parts of the thigh due
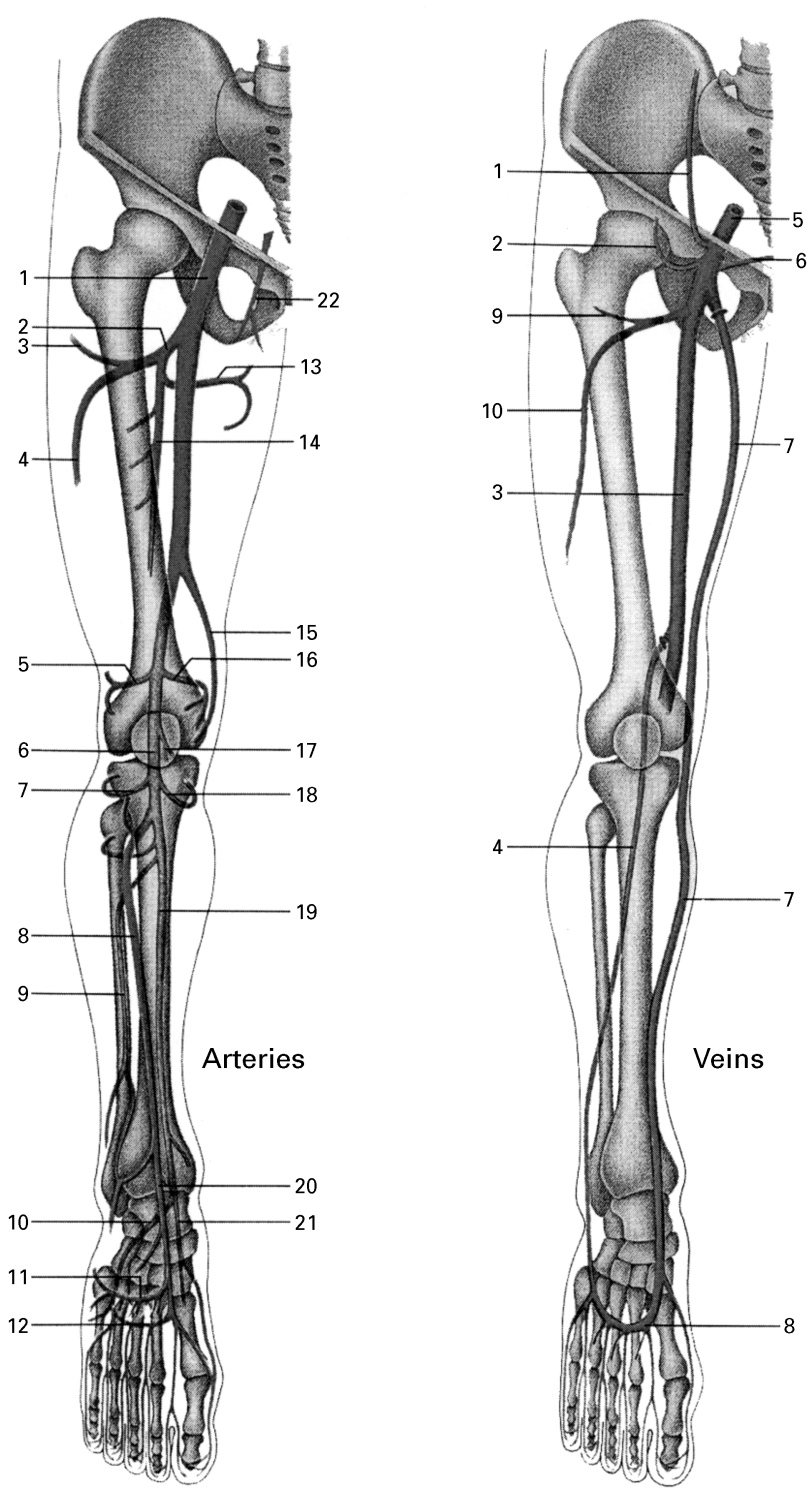

Fig. 2. Main arteries and veins of the lower extremities. Arteries: (1) femoral artery; (2) profunda femoris artery; (3) ascending branch of the lateral circumflex femoral artery; (4) descending branch of the lateral circumflex femoral artery; (13) medial circumflex femoral artery; (14) profunda femoris artery with perforating arteries; (22) obturator artery. Veins: (1) superficial epigastric vein; (2) superficial circumflex iliac vein; (3) femoral vein; (4) small saphenous vein; (5) external iliac vein; (6) external pudendal vein; (7) great saphenous vein; (9) lateral circumflex femoral vein; (10) profunda femoris vein. Note that a cuff has to be inflated just under the knee to temporarily occlude the circulation of the lower leg in order to avoid contamination of blood from the foot via the small saphenous vein (4; see Figs. 1 and 3). This is a standard procedure in exercise but cannot be performed during cycling exercise. (Modified from Rohen \& Yokochi, 1988.)

to some differences in activity. The proximal fraction of the thigh muscle is intensely engaged in the exercise and drained via the femoral vein at the site of the measurement (Figs. 2 and 3). However, variations in both $\mathrm{O}_{2}$ saturation and blood flow measured at various sites approximately $100 \mathrm{~mm}$ distal to the inguinal ligament are small and thus, limb $\mathrm{O}_{2}$ uptake $\left(\dot{V}_{\mathrm{O}_{2}}\right)$ is in essence unaffected by the blood 


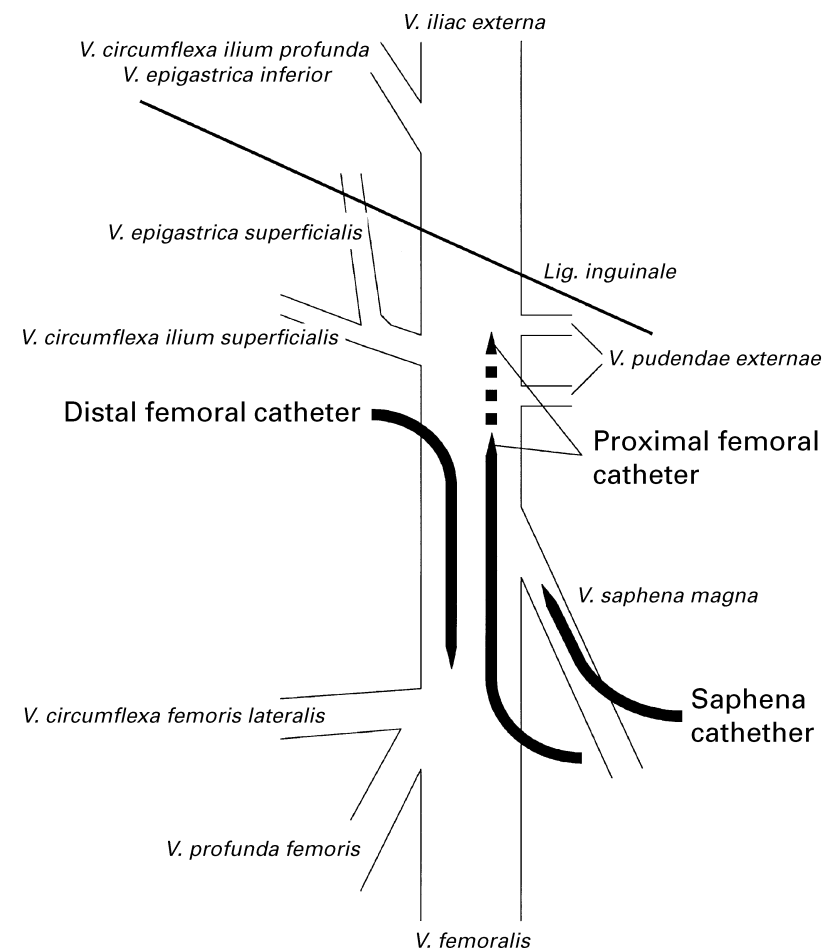

Fig. 3. Schematic drawing of the veins in the inguinal region of the leg and possible positions of catheters. (-), The proximal femoral venous catheter, representing the ideal position; (-- - -), the potential position when inserting the catheter in the proximal (anterograde) direction. Lig. inguinale, inguinal ligament.

Table 1. Leg blood flow (litre/min) measured using the thermo- and dye-dilution methods* during knee-extension exercise (From Kim et al. 1995)

(Values are means with their standard errors for four determinations)

\begin{tabular}{|c|c|c|c|c|c|c|}
\hline \multirow[t]{3}{*}{ Catheter position. } & \multicolumn{4}{|c|}{ Proximal } & \multirow{2}{*}{\multicolumn{2}{|c|}{$\begin{array}{c}\text { Distal } \\
\text { Dye }\end{array}$}} \\
\hline & \multicolumn{2}{|c|}{ Thermo } & \multicolumn{2}{|c|}{ Dye } & & \\
\hline & Mean & SE & Mean & SE & Mean & SE \\
\hline No workload & 1.6 & 0.3 & $1 \cdot 7$ & 0.2 & 1.4 & 0.3 \\
\hline $20 \mathrm{~W}$ & $3 \cdot 1$ & 0.4 & $3 \cdot 4$ & 0.2 & $3 \cdot 1$ & 0.3 \\
\hline $40 \mathrm{~W}$ & $5 \cdot 3$ & 0.3 & $5 \cdot 6$ & 0.4 & $5 \cdot 6$ & 0.4 \\
\hline
\end{tabular}

* Blood flow was determined in the femoral vein using a constant-infusion dilution technique (thermo) and using the reversed dye-dilution method with a single bolus injection (dye) in the femoral vein and sampling just proximal and distal to the orifice of the saphenous vein (see Fig. 3).

vessel in which the measurements are performed (see the following model and Fig. 5).

Model describing the influence of changes in leg skin blood flow for leg oxygen consumption during exercise in different environments

$$
\begin{gathered}
\dot{V}_{\mathrm{O}_{2} \text { leg }}=\mathrm{BF}_{\text {leg }} \times \mathrm{a}-\mathrm{v}_{\mathrm{f}} \mathrm{O}_{2} \operatorname{diff}=\left(\left(\mathrm{BF}_{\text {muscle }} \times \mathrm{a}-\mathrm{v}_{\mathrm{m}} \mathrm{O}_{2} \text { diff }\right)+\right. \\
\left.\left(\mathrm{BF}_{\text {non-muscle }} \times \mathrm{a}-\mathrm{V}_{\mathrm{nm}} \mathrm{O}_{2} \text { diff }\right)\right), \\
\text { i.e. } \dot{V}_{\mathrm{O}_{2} \text { leg }}=\dot{V}_{\mathrm{O}_{2} \text { muscle }}+\dot{V}_{\mathrm{O}_{2} \text { non-muscle }},
\end{gathered}
$$

where $\mathrm{BF}$ is blood flow, $\mathrm{a}-\mathrm{v}_{\mathrm{f}} \mathrm{O}_{2}$ diff, $\mathrm{a}-\mathrm{v}_{\mathrm{m}} \mathrm{O}_{2}$ diff and $\mathrm{a}-\mathrm{v}_{\mathrm{nm}} \mathrm{O}_{2}$ diff are arterio-venous difference in the femoral artery, muscle and non-muscle respectively, where muscle comprises all muscle tissue in the leg and non-muscle comprises skin, connective tissue and bone.

Cycling exercise in the heat $\left(210 \mathrm{~W}, 40^{\circ}\right)$ :

$V_{\mathrm{O}_{2} \text { leg }}=7.5$ litre $/ \mathrm{min} \times 150 \mathrm{ml} / \mathrm{l}=((7.0 \mathrm{litre} / \mathrm{min} \times$ $151 \mathrm{ml} / \mathrm{l})+(0.5$ litre $/ \mathrm{min} \times 15 \mathrm{ml} / \mathrm{l}))$

i.e $V_{\mathrm{O}_{2} \text { leg }}=1 \cdot 13=1.06+0.07$.

Cycling exercise in the cold $\left(210 \mathrm{~W}, 17^{\circ}\right)$ :

$V_{\mathrm{O}_{2} \text { leg }}=7.2$ litre $/ \mathrm{min} \times 157 \mathrm{ml} / 1=((7.0$ litre $/ \mathrm{min} \times$

$153 \mathrm{ml} / \mathrm{l})+(0 \cdot 2$ litre $/ \mathrm{min} \times 30 \mathrm{ml} / \mathrm{l}))$

i.e. $V_{\mathrm{O}_{2} \text { leg }}=1.13=1.07+0.06$

Note that the main difference between exercising in the heat and the cold is the 0.3 litre/min higher leg skin blood flow in the former. However, this increase in the leg-skin blood flow is accompanied by a proportionally lower a-v $\mathrm{O}_{2}$ difference, so that the skin and subcutaneous tissue $\dot{V}_{\mathrm{O}_{2}}$, and thus non-muscle $\dot{V}_{\mathrm{O}_{2}}$ remains unaltered.

\section{Arterial-femoral venous difference for substrates and metabolites}

For blood drawn from catheters placed in the femoral vein in the groin region in distal and proximal directions, available data for lactate at various exercise intensities are very similar and exceed the arterial concentration (Fig. 4(b)). The higher the exercise intensity, the larger is the difference. The lactate concentration in saphenous vein blood follows the arterial concentration and is at times slightly lower than that in the femoral vein. This situation reintroduces the problem of the similar lactate concentrations before and after the inflow of the saphenous blood. It is true that saphenous blood flow is relatively low, but some blood must be drained from the proximal thigh muscle, which has a slightly higher lactate concentration than blood from the more distal part to compensate for the low lactate level in the saphenous vein. This point of view is in accordance with the explanation given earlier for $\mathrm{O}_{2}$ saturation, and agrees with the observation that after training the proximal part of the kneeextensor muscle enlarges more than the more distal portions both in young (Narici et al. 1989, 1996) and older individuals (Kryger, 1998).

Available data on glucose reveal similar concentrations when sampling in the proximal and distal direction of the femoral artery, with a tendency for glucose concentration to be slightly higher in the proximal direction (Fig. 4(b)). The glucose concentration in the saphenous blood follows the arterial concentration, and is then usually slightly higher than the glucose concentration in the femoral vein. Whether this higher level is to an extent that causes a significant difference when measurements are performed proximally or distally in the femoral vein is uncertain at present, but it is of note that when measuring proximally the true muscle arterial-femoral venous difference for glucose may be underestimated, especially during exercise.

There also appears to be a systematic difference in the concentrations of free FA (FFA) and glycerol when measured distally or proximally in the femoral vein (Figs. 4 (c and d), 6 ( $a$ and b) and 7). This difference can be a major problem. In the distal direction glycerol and FFA levels are lower than those in the slightly more proximal position. It is true that the saphenous vein merges between 
Table 2. Comparison of published values for respiratory exchange ratio (RER) and leg $R Q$

\begin{tabular}{|c|c|c|c|}
\hline Study & Model & RER & $\mathrm{RQ}$ \\
\hline \multirow[t]{2}{*}{ Havel et al. (1967) } & Cycle: Rest & 0.74 & $0 \cdot 80$ \\
\hline & Exercise $(66.5 \mathrm{~W})$ & 0.83 & 0.85 \\
\hline \multirow[t]{4}{*}{ Bergstöm et al. (1969) } & Cycle: Rest & 0.72 & 0.72 \\
\hline & Rest (+nicotinic acid) & 0.74 & 0.82 \\
\hline & Exercise $(50 \mathrm{~W})$ & $0 \cdot 78$ & 0.77 \\
\hline & Exercise (+nicotinic acid) & 0.82 & 0.93 \\
\hline \multirow[t]{6}{*}{ Gollnick et al. (1981) } & Knee-extensor: Exercise (62\% two-leg $\left.V_{\mathrm{O}_{2} \max }\right)$ & & \\
\hline & Leg with normal glycogen & 0.83 & 0.90 \\
\hline & Leg with low glycogen & & 0.85 \\
\hline & Exercise (+nicotinic acid) & & \\
\hline & Leg with normal glycogen & 0.88 & 0.93 \\
\hline & Leg with low glycogen & & 0.93 \\
\hline Hargreaves et al. (1991) & Knee-extensor: Exercise ( $80 \%$ maximum leg work intensity) & 0.85 & 0.87 \\
\hline Kiens et al. (1993) & Knee-extensor: Exercise $\left(65 \%\right.$ leg $\left.V_{\mathrm{O}_{2} \max }\right)$ & $0 \cdot 80$ & 0.82 \\
\hline \multirow[t]{2}{*}{ Bergman et al. (1999) } & Cycle: Exercise $\left(45 \% V_{O_{2 p u l m}}\right)$ & 0.93 & 0.89 \\
\hline & Exercise $\left(65 \% V_{\mathrm{O}_{2} \text { pulm }}\right)$ & 0.96 & 0.98 \\
\hline González-Alonso et al. (1999)† & Cycle: Exercise (62\% $\left.V_{\mathrm{O}_{2} \text { pulm }}\right)$ & 0.90 & 0.92 \\
\hline van Hall et al. (unpublished results)†‡ & Cycle: Exercise ( $\left.80 \% V_{\mathrm{O}_{2} \text { pulm }}\right)$ & 0.93 & 0.95 \\
\hline
\end{tabular}

$V_{\mathrm{O}_{2} \max }, V_{\mathrm{O}_{\text {pulm }}}$, maximum and pulmonary $\mathrm{O}_{2}$ uptake respectively.

† Blood $\mathrm{CO}_{2}$ calculated according to Douglas et al. (1988).

$\ddagger$ G van Hall, M Sacchetti, G Rådegran and B Saltin, unpublished results.

(a) Knee extensor exercise

V. circumflexa femoris lateralis V. circumflexa ilium superficialis

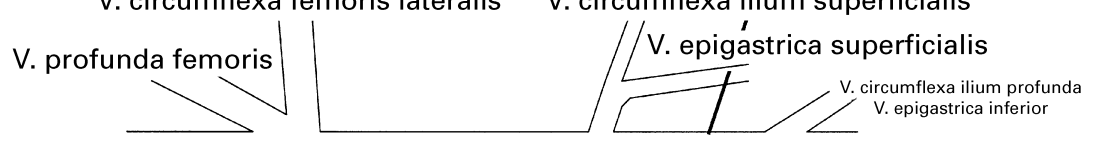

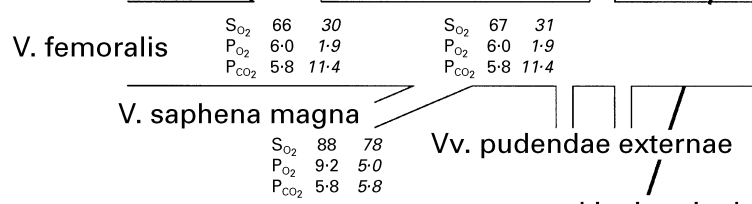

Lig. inguinale

(b) Knee extensor exercise

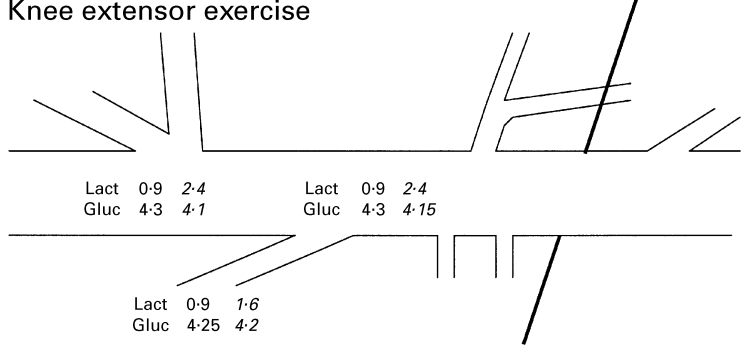

(d) Knee extensor exercise

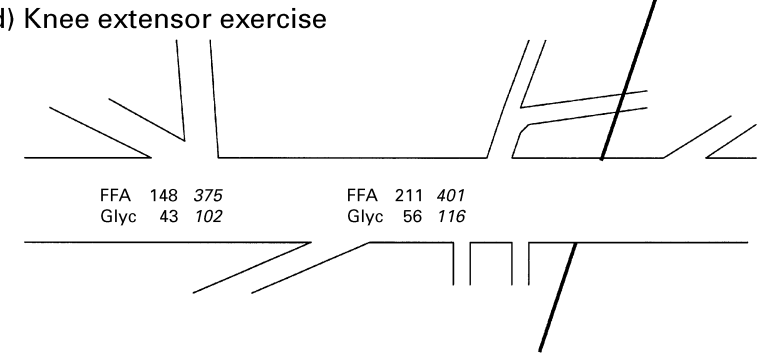

(c) Cycle exercise

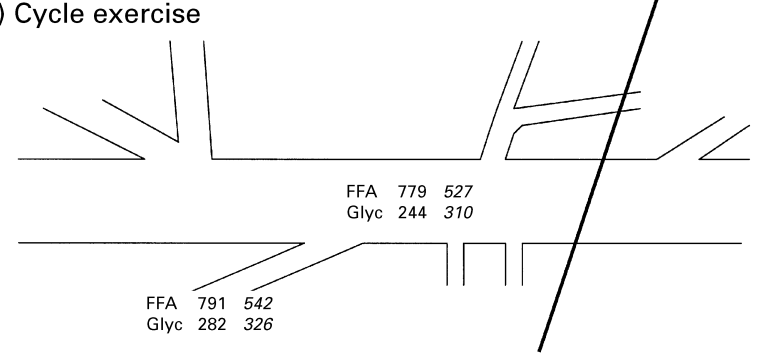

(e) Knee extensor exercise

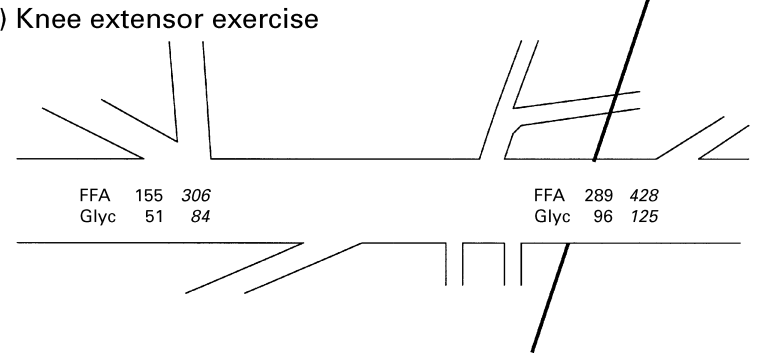

Fig. 4. Schematic representation of blood gases and metabolite concentrations in the different catheter positions (distal, proximal and saphenous) in the femoral and saphenous veins during knee extension exercise (a,b,d,e) and cycle exercise (c) in thermoneutral conditions (see Fig. 3). The concentrations shown in italics represent values during exercise. Blood oxygen saturation $\left(\mathrm{S}_{\mathrm{O}_{2}}\right)$ is expressed in \%, oxygen tension $\left(\mathrm{P}_{\mathrm{O}_{2}}\right)$ and carbon dioxide tension $\left(\mathrm{P}_{\mathrm{CO}_{2}}\right)$ in $\mathrm{kPa}$, lactate (Lact) and glucose (Gluc) in mmol/l, and free fatty acids (FFA) and glycerol (Glyc) in mmol/l. Lig. inguinale, inguinal ligament. (From Kim et al. (1995); G van Hall, M Sacchetti and B Saltin, unpublished results.) 

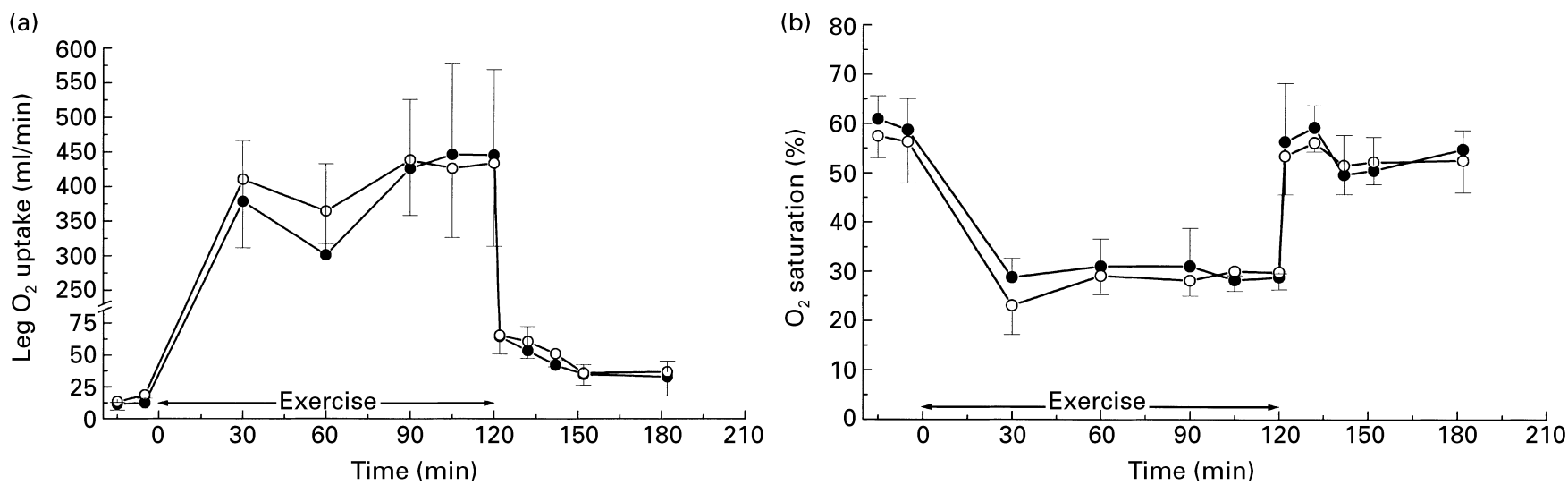

Fig. 5. Leg oxygen uptake and blood femoral venous oxygen saturation. Leg oxygen uptake (a) and blood venous oxygen saturation (b) at rest and during knee-extensor exercise and recovery when the femoral venous catheter was placed in the proximal $(\bullet)$ or distal $(O)$ direction (for details, see Fig. 3). Values are means and standard deviations for four determinations. (G. van Hall, J González-Alonso, M Sacchetti and B Saltin, unpublished results.)

(a)

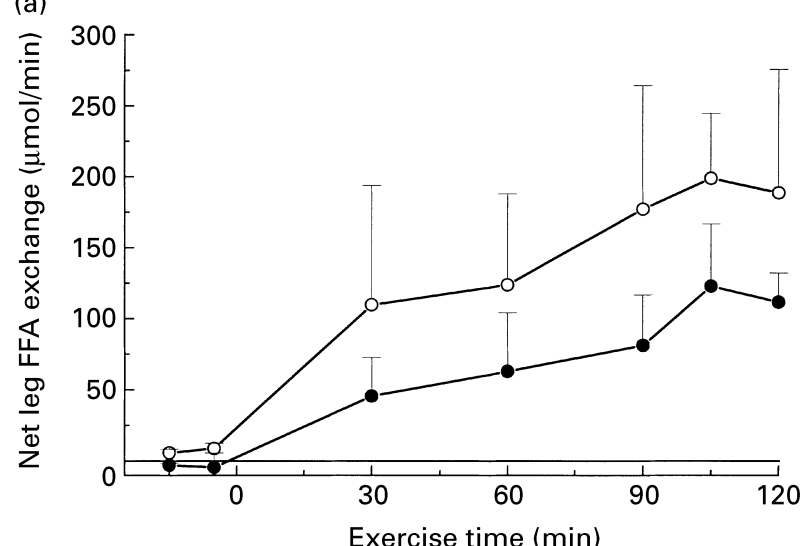

(b)

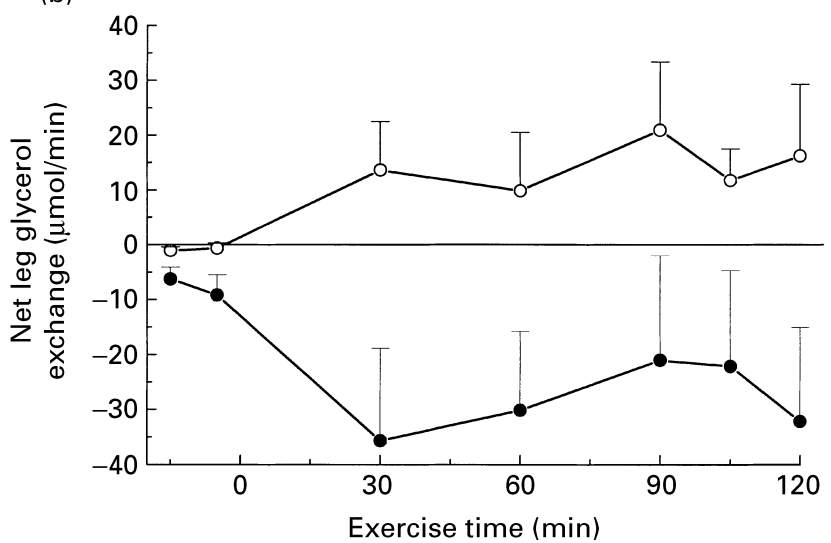

Fig. 6. (a) Leg free fatty acid (FFA) and (b) glycerol exchange. The FFA and glycerol exchange across the leg was calculated from the arteriofemoral venous (in proximal $(\bullet)$ and distal $(O)$ position) difference multiplied by the leg blood flow (measured using ultrasound Doppler) at rest and during knee-extensor exercise. Values are means and standard deviations for four determinations. A positive value indicates a net leg uptake and a negative value a net leg release. (G. van Hall, J González-Alonso, M Sacchetti and B Saltin, unpublished results.)

these two sampling points and it could be anticipated that lipolysis in the leg subcutaneous tissue causes the proximal values to be higher. In the one case studied the FFA and glycerol levels in the saphenous vein tended to be higher than those in the femoral vein. However, the difference was small and not large enough to account for the difference observed when comparing the two sites in the femoral vein. This situation may indicate that the abdominal fat pad is drained by veins which enter proximally to the orifice of the saphenous vein, but distally to the inguinal ligament (Figs. 6( $a$ and $b$ ) and 7).

Regardless of where the lipolysis may occur, if FFA and glycerol are added to the femoral vein blood at the proximal site where blood is most commonly sampled, it will not only represent blood from active skeletal muscle but from fat deposits outside the active skeletal muscle. This factor compromises the use of the $\mathrm{a}-\mathrm{v}$ difference for FFA to estimate the net exchange of FFA over the contracting muscles. Moreover, it would mean that a net release of glycerol is not a quantitative measure of TG hydrolysis occurring in the active muscles.
At the present time it seems that no studies using leg exercise have been carried out which have established the exact position of the femoral venous catheter. Thus, with leg exercise it is unclear what the contribution of the "contamination' from non-muscle tissues is to muscle FFA and glycerol turnover. Well-controlled studies have been performed on the forearm showing that 'pure' blood from contracting muscles was obtained by visualization of the placing of the tip of the catheter in a vein draining muscle only (Fig. 8; Wahren, 1967; Hagenfeldt \& Wahren, 1968). These studies confirm the importance of the sampling site, since they observed a net glycerol release during exercise when blood was sampled from a superficial forearm vein, but no net release of glycerol when blood was sampled from a deep forearm vein that was shown to drain only muscle (Hagenfeldt \& Wahren, 1968). However, it is equally clear that the uptake and oxidation of FFA from the blood could not account for all lipids being oxidized. Thus, the total amount of lipids being oxidized can only be explained if intramuscular lipid stores or blood TG (VLDL-TG and serum total TG) are utilized as well. The lack of glycerol 


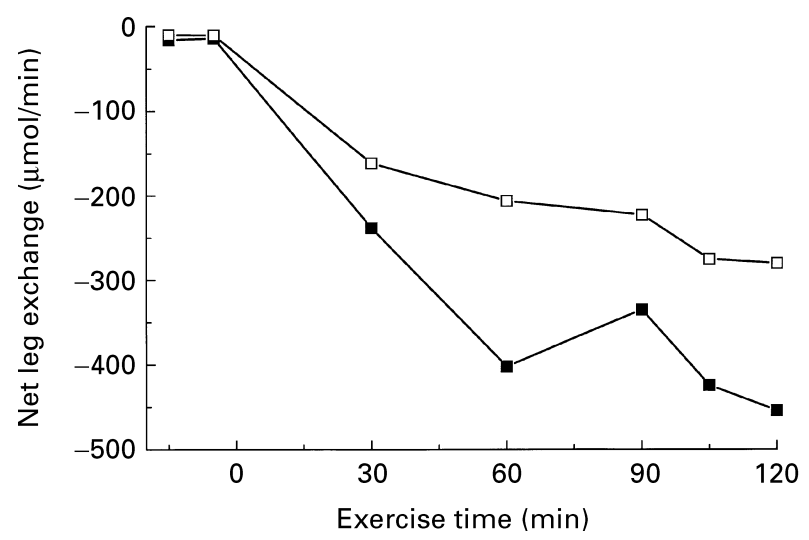

Fig. 7. Leg free fatty acid (FFA; $\square$ ) and glycerol $(\square)$ exchange with the femoral venous catheter in the proximal position with the tip above the inguinal ligament. FFA and glycerol exchange across the leg was calculated from arterio-femoral venous difference multiplied by the leg blood flow (measured using ultrasound Doppler) at rest and during knee-extensor exercise. Values represent one determination. The data indicate that if the tip of the femoral venous catheter is advanced more proximally to the inguinal ligament (compared with the sampling site in Fig. 6) that not only blood from the leg but also blood from the abdominal fat is sampled. This factor increases both the apparent release of fatty acids and of glycerol. (G van Hall, M Sacchetti and B Saltin, unpublished results.)

release from contracting skeletal muscle would argue against this being the case. The explanation may be that there is an uptake and metabolism of glycerol by the skeletal muscles (Hagenfeldt \& Wahren, 1968; Elia et al. 1993; Odland et al. 1998). Indeed, it has been demonstrated that glycerol kinase (EC 2.7.1.30) is present in human skeletal muscle (Seltzer et al. 1989), which suggests the possibility that glycerol may be metabolized. Moreover, glycerol dehydrogenase (EC 1.1.1.6) is also present in human skeletal muscle (Toews, 1966; Hagenfeldt \& Wahren, 1968), thus allowing the potential for glycerol to be oxidized (Hagenfeldt \& Wahren, 1968; Pearce \& Connett, 1980).

In summary, it is not critical whether the blood flow to the leg is measured as the arterial inflow or femoral outflow. In the latter case there is only a tendency for slightly higher blood flow values if the measurements are performed just proximal to the merger with the saphenous femoral vein. $\mathrm{O}_{2}$ saturation and haemoglobin are also similar both distal and proximal to the merger with the saphenous vein, minimizing the problem of measuring the leg $V_{\mathrm{O}}$. There are no systematic differences for glucose and lactate concentrations when comparing the proximal and distal sampling sites in the femoral vein. In contrast, both the FFA and glycerol levels may be slightly higher when sampling proximally. It is important to bear in mind that FFA exchange is calculated using plasma flows rather than blood flows, whereas the latter is used when estimating glucose, lactate and glycerol exchange. These considerations appear to apply to ordinary cycle exercise and the knee-extensor exercise model as well. (a)

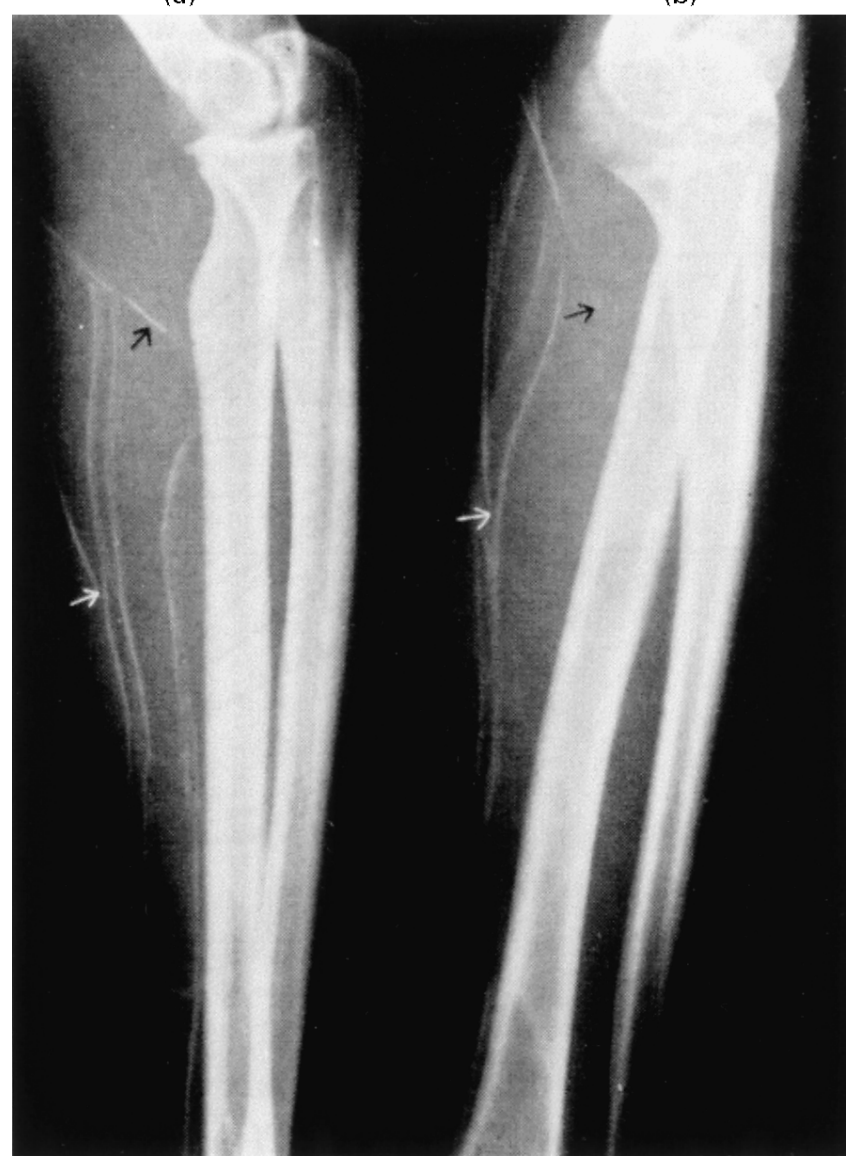

Fig. 8. In his studies of forearm muscle metabolism, Wahren (1967) controlled the positioning of the forearm venous catheter by X-ray. (a), Contrast medium may be seen in both deep and superficial veins after injection at rest into the radial artery at the wrist. The two venous catheters are visualized by contrast filling, with their tips indicated by arrows. (b), There is no contrast in the deep veins after injections into the radial artery during exercise $(0.75 \mathrm{~W}$, sixty contractions per min). Exposure was $6 \mathrm{~s}$ after the start of the injection.

\section{Small v. large muscle-group exercise}

Some of the best controlled exercise studies have been performed with the forearm, as discussed earlier (a thorough examination of the forearm exercise model is provided by Wahren (1967). However, the forearm exercise model has several methodological difficulties. First, a major drawback is that the loading of the various muscles of the forearm engaged in the exercise may vary considerably, since this is also dependent on hand-forearm positioning. Thus, a biopsy does not adequately represent all forearm muscles. Moreover, the small individual muscles of the forearm do not lend themselves to biopsy taking. Thus, isotopes have to be used to evaluate the relative contribution of blood-borne and intramuscular substrate stores, but even then this value represents an average of active and inactive muscles. Second, with forearm exercise the stress on the whole body is very minor compared with running or cycling exercise, which in turn may affect substrate delivery to the active muscle. Third, the position of the deep venous catheter has to be controlled so that it only drains forearm muscle, 
thereby avoiding the quantitatively large contribution of contamination from skin blood (Fig. 8; Wahren, 1967). Thus, for several reasons leg exercise is the preferred model, and it has been used extensively. In early work it consisted of ordinary cycle ergometry or treadmill exercise. During later years the knee-extensor model has come into use (Andersen et al. 1985; Richardson \& Saltin, 1998).

One of the main arguments for developing the kneeextensor model is the advantage of knowing precisely the amount of muscle mass involved in the exercise. Furthermore, of great importance is the fact that in kneeextensor exercise, when properly performed, only the quadriceps muscle and tensor fasciae latea is active and the four portions of the muscle are equally engaged (Fig. 9). This factor has been verified using electromyelogram analysis and magnetic resonance transaxial relaxation time weighted images of the thigh (Andersen et al. 1985; Andersen \& Saltin, 1985; Ray \& Dudley, 1998; Richardson \& Saltin, 1998). This finding makes it possible, when the knee-extensor exercise model is used, to express the contribution of muscle TG and glycogen to the metabolism on a whole-muscle level based on the muscle biopsy analysis, since it is quite likely to be representative of the whole muscle.

Cycle exercise does not offer any real possibility of being able to extrapolate from single biopsies to all leg muscles. Usually a given muscle weight is assumed (5-8 kg per leg). The problem is not only that the estimate of leg muscle mass may be wrong, but that various leg muscles may not contribute similarly at a given work intensity or at increasing workloads. Furthermore, the positioning of the foot on the pedal is important. If the foot is placed with the heel on the pedal the calf muscles are hardly engaged in exercise and the lower leg is acting as a lever arm. If the foot is placed with the forefoot on the pedal the calf muscles are engaged in exercise (Fig. 9). It is true that when leg $V_{\mathrm{O}_{2}}$ is determined during cycle work there is a linear increase with power output, but the relative proportion of this $V_{\mathrm{O}_{2}}$ that represents the pulmonary $V_{\mathrm{O}_{2}}$ may vary (Fig. 10). In some studies leg $V_{\mathrm{O}_{2}}$ may amount to as much as 80-90\% of the pulmonary $V_{\mathrm{O}_{2}}$, but in other studies, it may only represent $60-70 \%$ of the pulmonary $V_{\mathrm{O}}$. This finding signifies that in some studies a large proportion of the active skeletal muscle is not included in the measurements of the leg $V_{\mathrm{O}_{2}}$. This
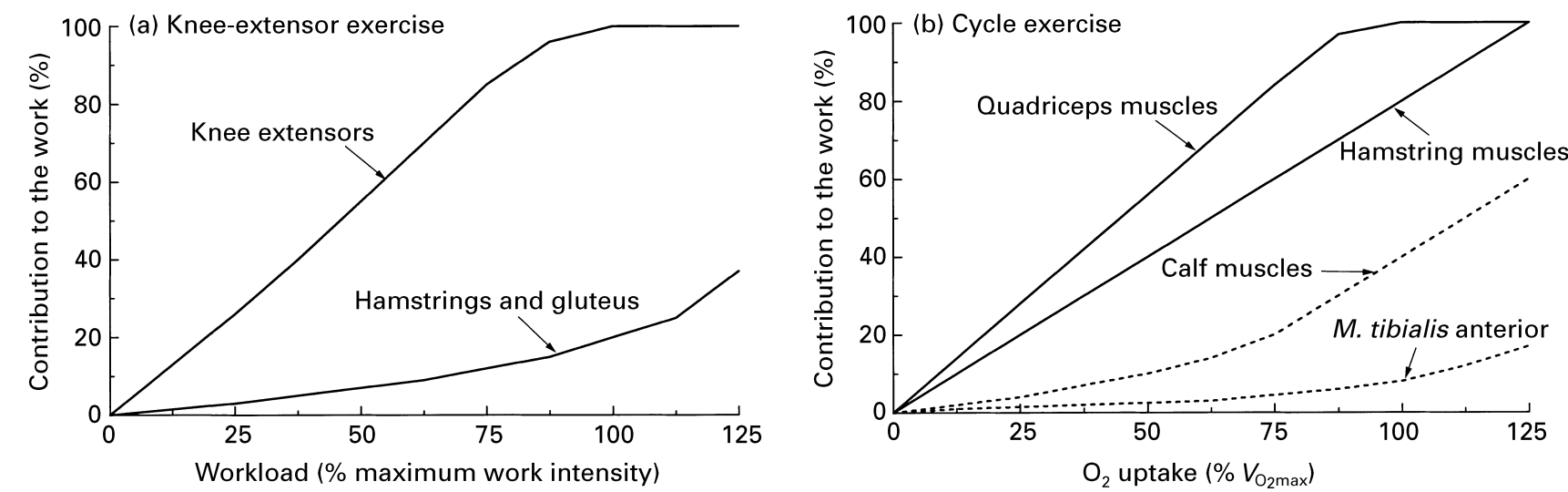

Fig. 9. Potential contribution of different muscle groups with increasing exercise intensity for (a) knee-extensor and (b) cycle exercise. $V_{\mathrm{O}_{2}}$ max, maximum oxygen uptake.
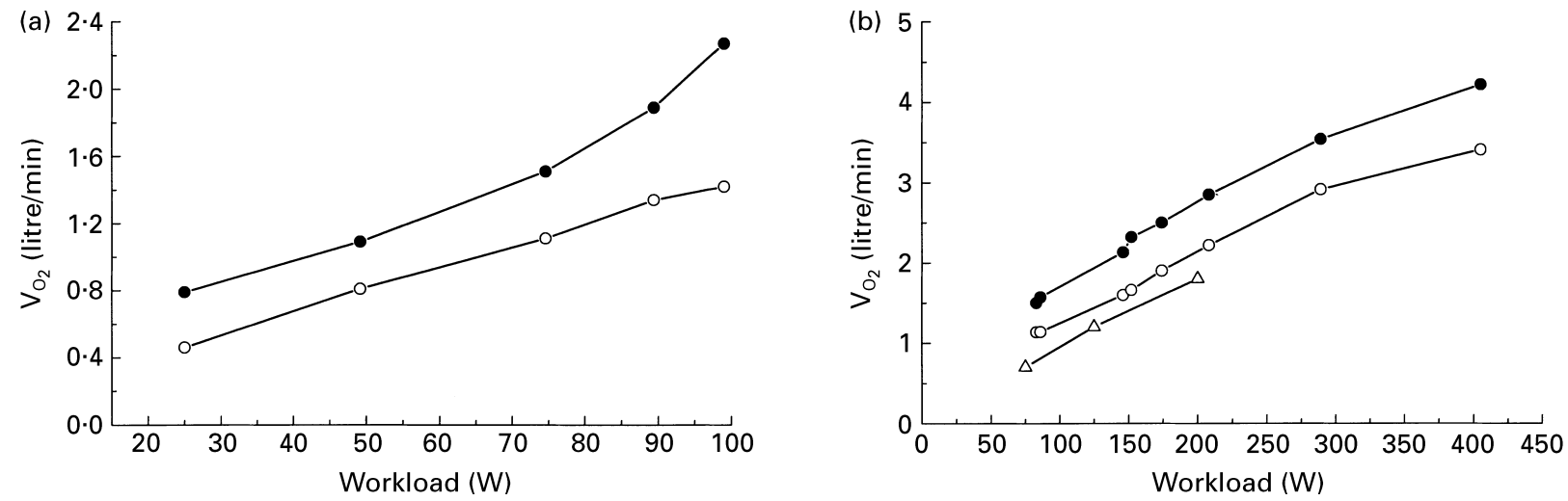

Fig. 10. Whole-body and leg $\mathrm{O}_{2}$ consumption $\left(\mathrm{V}_{\mathrm{O}_{2}}\right)$ as function of the workload during (a) one-leg knee-extension exercise and (b) cycle ergometer exercise. (a) Whole-body $(\bullet)$ and one-leg $(\mathrm{O}) \mathrm{V}_{\mathrm{O}_{2}}$ during incremental knee-extensor exercise (modified from Richardson et al. 1993). Note that one-leg $V_{\mathrm{O}_{2}}$ increases in a linear fashion with increasing workload, whereas whole-body $\mathrm{V}_{2}$ shifts from a linear to an exponential increase when reaching a high workload, due to the additional energy requirement for primarily postural muscles. During the linear part of the relationship, one-leg $V_{\mathrm{O}_{2}}$ contributes $70-74 \%$ whole-body $V_{\mathrm{O}_{2}}$ to decline to approximately $60 \%$ at the highest workload. (b) Whole-body (๑) and two-leg (O) $\mathrm{V}_{\mathrm{O}_{2}}$ during incremental cycle ergometer exercise in trained subjects data from Jorfeldt \& Wahren, 1971 ( $\Delta$ ); Poole et al. 1992; Harms et al. 1997; González-Alonso et al. 1998). Note that the contribution of two-leg $V_{\mathrm{O}_{2}}$ to whole-body $V_{\mathrm{O}_{2}}$ increases slightly from $72-76 \%$ at the lowest workloads, to $81-82 \%$ at the highest workloads. 
proportion tends to become gradually larger at higher work intensities in cycle exercise. In knee-extensor exercise, the elevation in pulmonary $V_{\mathrm{O}_{2}}$ parallels the increase in the leg $V_{\mathrm{O}_{2}}$ up to relatively high intensities of exercise, after which the pulmonary $V_{\mathrm{O}_{2}}$ increases exponentially while the leg $V_{\mathrm{O}_{2}}$ is elevated linearly.

These findings bring about the question as to whether small-muscle-group exercise such as knee-extensor work mimics ordinary exercise, in which a dominant proportion of the muscle mass of the body is in use; this question was discussed in a recent article (Richardson \& Saltin, 1998). There are several major differences between the two conditions. At peak exercise the work per unit muscle mass is the highest in knee-extensor exercise, primarily as a function of the larger $\mathrm{O}_{2}$ delivery as the heart does not constitute a limitation for the muscle perfusion. Increased glycogenolysis also makes a small contribution to the high peak power output, since more of the formed lactate can leave the muscle due to the high muscle perfusion. In kneeextensor exercise, the power output per unit muscle mass may be $30-40 \mathrm{~W} / \mathrm{kg}$, which is about 2-fold higher than that during peak cycle exercise. Despite the difference in power output per unit muscle mass, nucleotide changes (ATP, ADP, AMP, IMP) in the muscle, as well as those for phosphocreatine and $\mathrm{NH}_{3}$, during short-term exercise are almost identical in ordinary cycle ergometry and kneeextensor exercise.

In submaximal exercise performed for a prolonged period of time (hour(s)), the metabolic responses to cycle ergometer or knee-extensor exercise are also very similar. It might be anticipated that blood-borne substrates should contribute more in knee-extensor exercise since muscle perfusion is high, but this is not the case. Muscle glycogen utilization is high during the knee-extensor work, which may explain why glucose uptake by the muscle gradually increases during the exercise in a manner and magnitude close to that observed in two-legged cycle work. The FFA uptake is, if anything, lower in knee-extensor work than in cycling exercise, which relates to a low arterial FFA concentration. The sympathetic activation is also minor in smallmuscle-mass dynamic exercise, both in intense and more moderate exercise, as judged from plasma noradrenaline and adrenaline levels. Despite the low sympathetic activity, insulin is lowered in both forms of exercise. Other hormones have not been studied.

Based on the findings discussed earlier, it appears that knee-extensor exercise has many advantages, not the least that the active muscle mass is known, and it appears to have fewer limitations than ordinary cycle exercise. The possible drawback of a small muscle mass engaged in the exercise when the knee extensors of one leg are contracting can at least partly be overcome by exercising both legs. Recently, the knee flexors (hamstrings) have also been included to enlarge the muscle mass involvement, which may have some advantages in specific cardiovascular studies, but little in metabolic studies as the loading of extensor and flexor muscles will be difficult to estimate. Moreover, the femoral vein does not drain the proximal part of the hamstrings or the gluteal muscles.

It is of note that with one muscle group very active (knee extensors) and another inactive (hamstrings) mean transit time for the two compartments is different. In the active group it is as low as $5 \mathrm{~s}$ during very intense exercise, whereas the passively-contracting muscle has a mean transit time of approximately $15 \mathrm{~s}$ (J Bangsbo, K Kanstrup, J González-Alonso and B Saltin, unpublished results). Of greater concern, substrates or metabolites may be taken up by the inactive muscle, thus affecting the femoral vein concentration (Fig. 11). Lactate is used in Fig. 11 as an example of a metabolite for which a high arterial concentration is taken up by the inactive muscle; this high uptake in turn lowers the lactate concentration in the venous blood from the hamstrings. Although blood flow may be lower, it affects the femoral venous concentration, and the true lactate release from the knee extensors is underestimated. Glucose, FFA and TG are less likely to be taken up to a smaller extent by the hamstrings than by the knee extensors. The concentration of these substrates will then be higher in the venous drainage from the hamstrings than the knee extensors, and the uptake over the active muscle is underestimated.

Finally, it should be mentioned that two-legged exercise offers the possibility of inducing an intervention in one of the legs. Most commonly, this intervention involves training one leg or lowering the glycogen level of one leg. Performing measurements over both legs allows a direct comparison of blood-borne substances (substrates, hormones) with local muscle substrate stores influencing the metabolic response.

\section{How well can skeletal muscle substrate utilization in exercise be described?}

In most studies in the field of exercise metabolism usually only one, two or possibly three of the various substrate choices have been determined directly. The description of the more complete picture of the relative contribution stems from an evaluation based on the RER or RQ of the carbohydrate $(\mathrm{CHO})$ and lipid contribution, and the estimated remaining substrate utilization is obtained by subtraction. A good match for the quantitative role for the various substrates is then presented. For the uncritical reader the precision is very impressive. A more careful evaluation, however, usually reveals that there is much more of a mismatch than at first glance. Several reasons for this problem have been outlined earlier. The following section will highlight some additional aspects of the problem encountered when reading studies where skeletal muscle

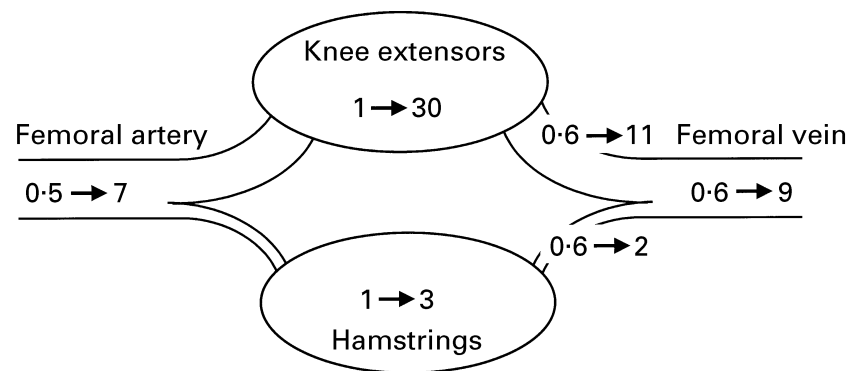

Fig. 11. Schematic drawing of the effect of inactive muscle groups on the femoral venous concentration of lactate $(\mathrm{mmol} / \mathrm{l})$. The kneeextensors perform the work, whereas the hamstrings are inactive. 
metabolism has been quantified. The specific topics to be discussed are RER and RQ measurements, the role of glucose uptake by muscle and muscle glycogen utilization to provide the $\mathrm{C}$ skeleton for pyruvate formation, fractional oxidation of FA, and the contributions of serum TG, VLDL-TG and muscle TG. The last topic to be highlighted is the metabolic adaptation to endurance training, which shows the breadth of the problem when the goal is to precisely quantify muscle substrate utilization.

\section{Carbohydrate and lipid utilization based on measurements of respiratory exchange ratios and respiratory quotients}

The general metabolic response to incremental exercise or more prolonged exercise was outlined in studies in the 1930s (Christensen, 1932; Dill et al. 1932; Bang, 1936; Böje, 1936). The higher the workload the higher the RER, indicating an enhanced utilization of $\mathrm{CHO}$. In contrast, as the exercise continues at a given submaximal workload RER progressively declines, reflecting a larger dependency on lipid oxidation with time. This decrease in RER during exercise is only pronounced if the intensity is low and the exercise time is relatively prolonged. Indeed, at exercise intensities above 60-65\% $V_{\mathrm{O}_{2} \max }$ the decrease in RER is small or zero (Hermansen et al. 1967; Gollnick et al. 1974; Saltin \& Gollnick, 1988). Measurements of RQ for a limb at rest and during exercise confirm the RER measurements. However, when measured simultaneously with RER, the RQ values are usually slightly higher (Table 2). The probable explanation is that there is a higher level of utilization of $\mathrm{CHO}$ in contracting skeletal muscle than in the rest of the body. More recently, Brooks and co-workers (O’Brien et al. 1993; Bergman et al. 1999) have conducted studies where RER and RQ were used to estimate CHO and lipid oxidation. In general they report higher RER and RQ values at a given work intensity than have been generally observed. Indeed, the general implication from their work is that when muscle contracts there is virtually exclusive utilization of $\mathrm{CHO}$. There are several lines of evidence to suggest that the high RER values reported by O'Brien et al. (1993) and Bergman et al. (1999) do not represent the generally accepted pattern. First, most of the data reported in the literature are in marked contrast to their findings. Further evidence against $\mathrm{CHO}$ being virtually the only substrate utilized in contracting skeletal muscle is the finding that blood-borne FA are oxidized in significant amounts. Moreover, TG are used in prolonged exercise as well as in more-short-term high-intensity cycle work. It is also of note that the estimated level of $\mathrm{CHO}$ utilization, based on the studies by O'Brien et al. (1993), appears to exceed the storage of $\mathrm{CHO}$ in the human body. In the study of a simulated marathon race approximately $600 \mathrm{~g} \mathrm{CHO}$ should have been consumed. It is true that this amount of glycogen can be stored in the human body, but only half of it is located in the leg muscle, and very special dietary regimens are needed to come close to a CHO storage of $500 \mathrm{~g}$ exclusively in the leg muscles (supplemented by approximately $100 \mathrm{~g}$ in the liver). The subjects in these studies had been given a meal before the experiment, which tends to elevate the RER and RQ, but this effect is not usually sufficient to explain the difference. Our conclusion is that when properly measured the RER values provide a valid estimate of the whole-body utilization of $\mathrm{CHO}$ and lipids, but for skeletal muscle metabolism to be evaluated, appropriate RQ measurements have to be performed.

\section{Source of glucose for glycolysis}

Glucose uptake by the leg increases as a function of the workload, as does the amount of muscle glycogen broken down (Figs. 12 and 13). When the blood glucose contribution and the estimated muscle glycogen contribution (although a quite conservative assumption is made for the active muscle mass engaged in the exercise) are added together, the sum is often considerably higher than the estimated CHO utilization based on $V_{\mathrm{O}_{2}}$ and RQ. Whether it is the intramuscular $\mathrm{CHO}$ contribution that is overestimated cannot be determined, and it may also vary among studies. When splanchnic glucose output has been measured simultaneously with the glucose uptake by muscle, it is common that the former cannot account for the utilization of blood glucose by the peripheral tissues and the fact that the arterial blood glucose concentration is quite stable (Ahlborg et al. 1974, 1982; Ahlborg \& Juhlin-Danfelt, 1994). This finding suggests that glucose uptake by muscle is the value overestimated, but it is difficult to envisage how this can occur since femoral venous blood is commonly sampled from a position which tends to underestimate the a-v glucose difference of the true glucose uptake. The most obvious problem is the issue of muscle mass. However, in some studies there is no possibility of any $\mathrm{CHO}$ source other than the blood glucose. Thus, even with the most conservative estimate of muscle mass involvement, there is a surplus of $\mathrm{CHO}$ utilization compared with the estimated $\mathrm{CHO}$ utilization. Related to this issue is the possibility that during exercise there is glycogen storage in the muscles concomitant with glycogen breakdown. Although storage may occur, synthesis must take place in parts of the muscle other than that obtained by biopsy in order to explain the high glucose uptake from the blood, i.e. a proportion of the measured glucose uptake is not oxidized but stored. At present it is not easy to reconcile this issue of a mismatch between estimated muscle turnover of $\mathrm{CHO}$ and the levels of the two $\mathrm{CHO}$ sources. Tracer

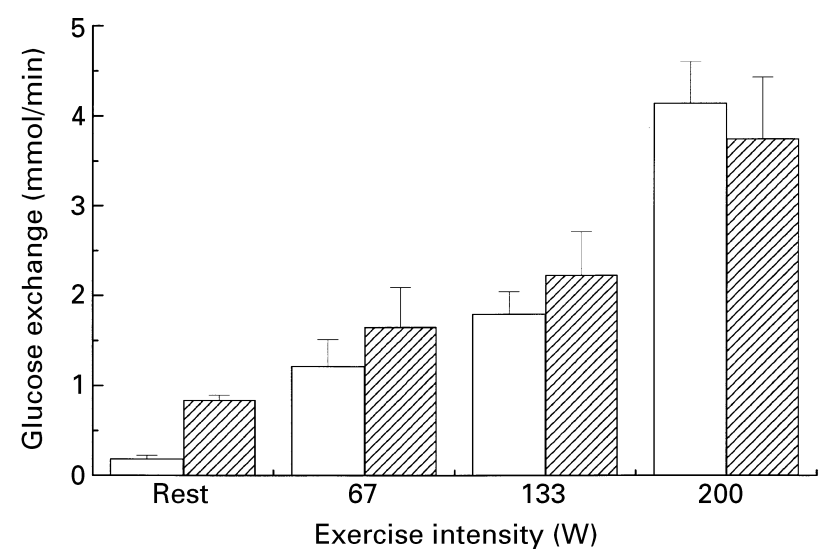

Fig. 12. Leg-muscle glucose uptake $(\square)$ as a function of the workload. (mas), Splanchnic production. Values are means and standard deviations represented by vertical bars. (From Wahren et al. 1971.) 


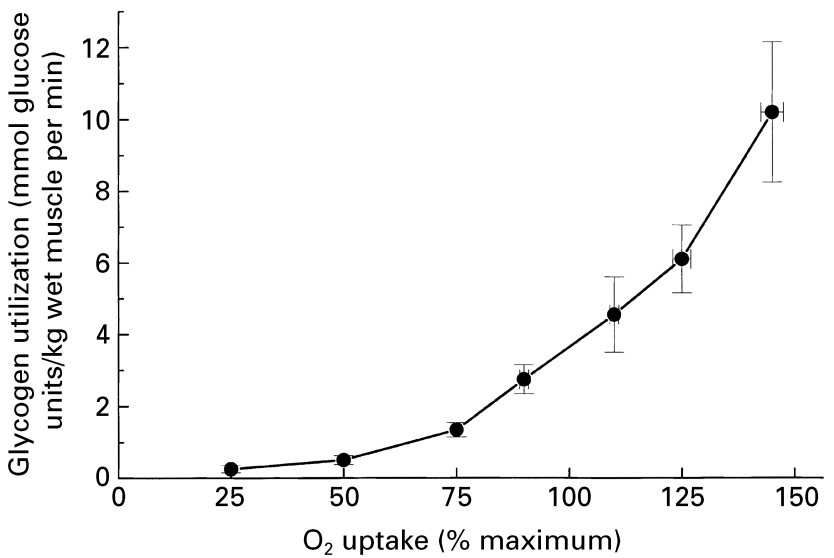

Fig. 13. Muscle glycogen depletion as a function of the workload. Values are means with their standard errors represented by vertical bars. (From Saltin \& Karlsson, 1971.)

studies to determine the glucose oxidation rate could be a first step in establishing the possibility of glycogen storage in muscle while subjects are performing work. There is not an easy solution to the problem of how well a muscle sample represents the active muscle, as well as the size of the muscle mass in cycle exercise.

\section{Source of fatty acids for skeletal muscle oxidation}

FA are both taken up and released by the muscle cell. The $a-v$ difference gives the net exchange, but this value is not sufficient to evaluate the rate at which FA are utilized by the muscle, since it may not be totally oxidized immediately. Tracer studies reveal that 60-90\% may be oxidized (Havel et al. 1967; Hagenfeldt \& Wahren, 1968, 1972; Ahlborg et al. 1974; Dagenais et al. 1976; Turcotte et al. 1992). The variation among studies is quite large, which probably relates to the variation in intensity and duration of the exercise as well as the training status of the subjects. Recent work which aims to establish an acetate correction factor, accounting for labelled $\mathrm{CO}_{2}$ not excreted and label fixed in other metabolites (van Hall, 1999), indicates that the true fractional oxidation rate may be closer to $100 \%$ than originally believed (Sidossis et al. 1995; Mittendorfer et al. 1998). A common procedure when tracers are not used is to assume a given percentage of the net FA uptake is oxidized. Although possibly better than only using the net uptake of FA (which may overestimate the contribution from bloodborne FA), the accuracy of the estimation is too low to allow for any precision in the evaluation of FA being used by the muscle. Indeed, it appears mandatory to use tracers in any attempt to quantify FA oxidation. The use of tracers would be advisable where studies involving the acetate correction do not demonstrate that $100 \%$ of the FA taken up are oxidized. Moreover, consideration should also be given to the question of which individual FA should be used to represent the FA. Palmitic (16:0), stearic $(18: 0)$, oleic $(18: 1)$ and linoleic $(18: 2)$ acids together represent approximately $80-90 \%$ of the blood FA. The ratio between these FA, the muscle fractional uptake and the total net exchange are similar for these FA (Havel et al. 1964; Hagenfeldt \&
Wahren, 1968, 1972; Hagenfeldt, 1975) suggesting that they can all be used to represent blood FA.

Blood-borne TG is not regarded as a major supplier of FA for muscle energy turnover during exercise. Values for lipid oxidation of from 5 to $10 \%$ are usually observed when based on measurements of a-v difference and blood flow (Havel et al. 1967; Hagenfeldt et al. 1975; Olssen et al. 1975; Kiens et al. 1993; for review see Van der Vusse \& Reneman, 1996). This value does not take into account whether the FA released from the blood-borne TG is oxidized. In contrast there are studies proposing a much larger contribution from blood-borne TG. Other studies have measured muscle TG but have not observed any utilization (Kiens et al. 1993). However, there is a significant glycerol release. The glycerol was then assumed to be derived from hydrolysis of TG, with no breakdown of muscle TG; TG in the blood would have been the lipid source. As discussed earlier, it cannot be excluded that the glycerol originates from the hydrolysis of TG in the adipose tissue.

Equally contradictory with regard to the possible role of blood TG are the data on the utilization of muscle TG in exercise. Most studies demonstrate a utilization (Fröberg et al. 1971; Fröberg \& Mossfeldt, 1971; Essén et al. 1977; Hurley et al. 1986), but it has not been possible to evaluate to what extent these TG are located in or between the muscle fibres. There are also studies where no muscle TG breakdown has been observed (Jansson \& Kaijser, 1982; Kiens et al. 1993; Wendling et al. 1996; Kiens \& Richter, 1998), several of which have used knee-extensor exercise. In the latter case it has been proposed that the lack of TG hydrolysis could be due to the exercise model and, for example, lack of hormonal or sympathetic activation of the lipase when only a small proportion of the muscle mass is engaged in the exercise (Kiens et al. 1993). Regardless of whether or not this is the explanation, it is apparent that the present knowledge is limited with respect to specific values for the various fat sources being used by muscle during exercise. The situation could be improved by the use of tracers, to determine not only the fractional oxidation of blood-borne FA, but also the contribution of FA from hydrolysis of TG from either the blood or muscle. Equally important would be the determination of level of glycerol metabolism in active skeletal muscles.

\section{Endurance training}

The pattern of change with endurance training is quite clear. The CHO dependence is reduced, less lactate is formed, and lipid oxidation is enhanced. RQ measurement is a good indicator of the relative roles of $\mathrm{CHO}$ and fat. However, the most striking observation when comparing some studies in the field is how different the results are. This factor has been highlighted by just three well-controlled studies by experienced researchers. In two of the investigations, the subjects trained one leg and the muscle metabolism was studied in both legs during exercise (Henriksson, 1977; Kiens et al. 1993). Both studies showed a reduction in CHO utilization. In one of the studies (Henriksson, 1977) this was due to a lower glucose uptake, while in the other study (Kiens et al. 1993) it was due to reduced muscle glycogen 
depletion (estimated value; there was no significant difference in muscle glycogen breakdown in the two legs). Although there were differences in the relative amount of lipid that was oxidized in the two studies, they both show a major increase in the contribution of FFA from the blood. This latter finding is in sharp contrast with the study by Hurley et al. (1986) who found a major increase in the contribution of muscle TG after endurance training. Thus, depending on choice of study, a different message is obtained with regard to which substrate source contributes the most when the muscle is subjected to endurance training. The only common finding is the enhancement of lipid oxidation and a reduction in lactate production. It is worth emphasizing that only a very small proportion of the FFA offered to the active muscle is taken up by the muscle (at rest approximately $45 \%$, with exercise approximately 8-15 \%; Hagenfeldt \& Wahren, 1968; Ahlborg et al. 1974; Dagenais et al. 1976; Essén et al. 1977; Turcotte et al. 1992). This percentage is not markedly increased in endurance-trained muscle or when the supply of $\mathrm{CHO}$ is limited (Turcotte et al. 1992). This implies major limitations in uptake and/or utilization of FA by human skeletal muscle, which are only overcome to a very minor extent by endurance training.

\section{Conclusion}

From this account of substrate utilization during exercise it is apparent that the overall pattern can be described well. It is equally clear, however, that a precise account of the relative roles of the available substrate sources cannot be given by using measurements of $\mathrm{a}-\mathrm{v}$ difference, blood flow and muscle biopsies. One problem is the muscle mass engaged in the exercise. With cycle exercise muscle mass is a major problem, but it is less of a problem in relation to knee-extensor exercise. The larger problem relates to quantification of the various lipid sources. First, FFA uptake may not be synonymous with FFA oxidation, and tracers have to be used to determine the fractional oxidation. Glycerol release from an active limb has generally been used to estimate TG hydrolysis. When no such release occurs, probably due to glycerol being metabolized in the muscle, TG hydrolysis can only be determined by the use of tracers or by careful measurements of TG uptake by the muscle and the muscle-TG determinations before and after the exercise. The precision of a- $\mathrm{v}$ differences for $\mathrm{TG}$ is compromised by the differences being very small during exercise, due to the high blood flow. This problem is also relevant to the determination of the $\mathrm{a}-\mathrm{v}$ difference for glucose. Quantification of the utilization of muscle glycogen and TG is difficult due to uncertainty as to how representative the muscle biopsy may be.

It is advisable to use tracers when precision in the quantification of blood-borne substrates is required, but the value of these tracer measurements is a function of the accuracy of the muscle a-v difference determination. Thus, a key issue in skeletal muscle metabolic studies is the positioning of the venous catheter(s) to secure blood samples that represent the muscle under study. The aim of the present article has been to critically evaluate methodological concerns related to the precise quantification of skeletal muscle substrate choice during exercise. The conclusion is that there have been major limitations in the studies performed so far. Advice is given as to how improvements can be made. These improvements relate to obtaining better quantitative data, but more importantly they also apply in the case of studies where the aim is to elucidate the regulatory mechanisms for substrate choice by muscle.

\section{Acknowledgements}

The Copenhagen Muscle Research Centre receives a grant from the Danish National Research Foundation (grant no. 504-14).

\section{References}

Ahlborg G \& Felig F (1982) Lactate and glucose exchange across the forearm, legs and splanchnic bed during and after prolonged leg exercise. Journal of Clinical Investigation 69, 45-54.

Ahlborg G, Felig P, Hagenfeldt L, Hendler R \& Wahren J (1974) Substrate turnover during prolonged exercise in man. Splanchnic and leg metabolism of glucose, free fatty acids, and amino acids. Journal of Clinical Investigation 53, 1080-1090.

Ahlborg G \& Juhlin-Dannfelt (1994) Effect of $\beta$-receptor blockade on splanchnic and muscle metabolism during prolonged exercise in man. Journal of Applied Physiology 76, 1037-1042.

Andersen P, Adams RP, Sjøgaard G, Thorboe A \& Saltin B (1985) Dynamic knee extension as a model for study of isolated exercising muscle in humans. Journal of Applied Physiology 59, $1647-1653$.

Andersen P \& Saltin B (1985) Maximal perfusion of skeletal muscle in man. Journal of Physiology 366, 233-249.

Atwater WO \& Benedict FG (1903) Experiments on the Metabolism of Matter and Energy in the Human Body. Agricultural Bulletin no. 136. Washington, DC: US Department of Agriculture.

Bang O (1936) The lactate content of blood during and after muscular exercise in man. Skandinavische Archiv der Physiologie 74, 51-82.

Benedict FG \& Carpenter TM (1910) The Metabolism and Energy Transformations of Healthy Man During Rest, pp. 182-193. Washington, DC: The Carnegie Institute.

Bergman BC, Butterfield GE, Wolfel EE, Casazza GA, Lopaschuk GD \& Brooks GA (1999) Evaluation of exercise and training on muscle lipid metabolism. American Journal of Physiology 276, E106-E117.

Bergström J (1962) Muscle electrolytes in man. Determination by neutron activation analysis on needle biopsy specimens. A study on normal subjects, kidney patients, and patients with chronic diarrhoea. Scandinavian Journal of Clinical and Laboratory Investigation Suppl. 68, 7-110.

Bergström J, Hultman E, Jorfeldt L, Pernow B \& Wahren J (1969) Effect of nicotinic acid on physical capacity and on metabolism of muscle glycogen in man. Journal of Applied Physiology 26, 170-176.

Boesch C, Décombaz J, Slotboom J \& Kreis R (1999) Observation of intramyocellular lipids by means of ${ }^{1} \mathrm{H}$ magnetic resonance spectroscopy. Proceedings of the Nutrition Society 58, 841-850.

Böje O (1936) Der blutzucker während und nach körperlicher arbeit (Maintenance of blood sugar before and after manual work). Skandinavische Archiv der Physiologie 74, Suppl. 10, $1-48$.

Christensen E-H (1932) Der stoffwechsel und die respiratorischen funktionen bei schwerer körperliche arbeit (Metabolism 
and respiratory function during heavy manual work). Arbeitsphysiologie 5, 463-478.

Dagenais GR, Tancredi RG \& Zierler KL (1976) Free fatty acid oxidation by forearm muscle at rest, and evidence for an intramuscular lipid pool in the human forearm. Journal of Clinical Investigation 58, 421-431.

Dill DB, Edwards HT \& Talbott JH (1932) Studies in muscular activity. VII. Factors limiting the capacity for work. Journal of Physiology 77, 49-62.

Douglas AR, Jones NL \& Reed JW (1988) Calculation of whole blood $\mathrm{CO}_{2}$ content. Journal of Applied Physiology 65, 473-477.

Elia M, Khan K, Calder G \& Kurpad A (1993) Glycerol exchange across the human forearm assessed by a combination of tracer and arteriovenous exchange techniques. Clinical Science 84, 99-104.

Essén B, Hagenfeldt L \& Kaijser L (1977) Utilization of bloodborne and intramuscular substrates during continuous and intermittent exercise in man. Journal of Physiology 265, 489-506.

Fridén J, Seger J \& Ekblom B (1989) Topographical localization of muscle glycogen: an ultrahistochemical study in the human vastus lateralis. Acta Physiologica Scandinavica 135, 381-391.

Fröberg SO, Carlson LA \& Ekelund L-G (1971) Local lipid stores and exercise. In Muscle Metabolism During Exercise. Advances in Experimental Medicine and Biology, vol. 11, pp. 307-313 [B Pernow and B Saltin, editors]. New York: Plenum Press.

Fröberg SO \& Mossfeldt F (1971) Effect of prolonged strenuous exercise on the concentration of triglycerides, phospholipids and glycogen in muscle of man. Acta Physiologica Scandinavica 82, 167-171.

Gollnick PD, Karlsson J, Piehl K \& Saltin B (1974) Selective glycogen depletion in skeletal muscle fibres of man following sustained contractions. Journal of Physiology 241, 59-67.

Gollnick PD, Pernow B, Essén B, Janson E \& Saltin B (1981) Availability of glycogen and plasma FFA for substrate utilization in leg muscle of man. Clinical Physiology 1, 12-42.

González-Alonso J, Calbert JAL \& Nielsen B (1998) Muscle blood flow is reduced with dehydration during prolonged exercise in humans. Journal of Physiology 513, 895-905.

González-Alonso J, Calbert JAL \& Nielsen B (1999) Metabolic and thermodynamic responses to dehydration induced reductions in muscle blood flow in exercising humans. Journal of Physiology 520, 577-589.

Hagenfeldt L (1975) Turnover of individual free fatty acids in man. Federation Proceedings 34, 2246-2249.

Hagenfeldt L, Hellström K \& Wahren J (1975) Triglyceride, free fatty acid and carbohydrate metabolism in hyperlipaemic (type IV) and normlipaemic subjects on carbohydrate- or fatrich diets. Clinical Science and Molecular Medicine 48, 247-257.

Hagenfeldt L \& Wahren J (1968) Human forearm muscle metabolism during exercise II. Uptake, release and oxidation of individual FFA and glycerol. Scandinavian Journal of Clinical and Laboratory Investigation 21, 263-276.

Hagenfeldt L \& Wahren J (1972) Human forearm muscle metabolism during exercise. VII. FFA uptake and oxidation at different work intensities. Scandinavian Journal of Clinical and Laboratory Investigation 30, 429-436.

Hargreaves M (1995) Exercise Metabolism. Champaign, IL: Human Kinetics.

Hargreaves M, Kiens B \& Richter E (1991) Effect of increased plasma free fatty concentrations on muscle metabolism in exercise in exercising men. Journal of Applied Physiology 70, 194-201.

Harms CA, Babcock MA, McClaran SR, Pegelow DF, Nickele GA, Nelson WB \& Dempsey JA (1997) Respiratory muscle work compromises leg blood flow during maximal exercise. Journal of Applied Physiology 82, 1573-1583.

Havel RJ, Carlson LA, Ekelund L-G \& Holmgren A (1964) Turnover rate and oxidation of different free fatty acids in man during exercise. Journal of Applied Physiology 19, 613-618.

Havel RJ, Pernow B \& Jones NL (1967) Uptake and release of free fatty acids and other metabolites in the legs of exercising men. Journal of Applied Physiology 23, 90-99.

Henriksson J (1977) Training induced adaptations of skeletal muscle and metabolism during submaximal exercise. Journal of Physiology 270, 661-675.

Hermansen L, Hultman E \& Saltin B (1967) Muscle glycogen during prolonged severe exercise. Acta Physiologica Scandinavica 71, 129-139.

Horton ES \& Terjung RL (editors) (1988) Exercise Nutrition and Energy Metabolism. New York: Macmillan Publishing Co.

Hurley BF, Nemeth PM, Martin WH III, Hagberg JM, Dalsky GP \& Hollozy JO (1986) Muscle triglyceride utilisation during exercise: effect of training. Journal of Applied Physiology 60, 562-567.

Jansson E \& Kaijser L (1982) Effect of diet on the utilization of blood-borne and intramuscular substrates during exercise in man. Acta Physiologica Scandinavica 115, 19-30.

Jorfeldt L \& Wahren J (1971) Leg blood flow during exercise in man. Clinical Science 41, 459-473.

Kiens B, Éssén-Gustavsson B, Christensen NJ \& Saltin B (1993) Skeletal muscle substrate utilisation during submaximal exercise in man: effect of endurance training. Journal of Physiology 469, $459-478$.

Kiens B \& Richter EA (1998) Utilization of skeletal muscle triacylglycerol during post exercise recovery in humans. American Journal of Physiology 275, E332-E337.

Kim CK, Strange S, Bangsbo J \& Saltin B (1995) Skeletal muscle perfusion in electrically induced dynamic exercise in humans. Acta Physiologica Scandinavica 153, 279-287.

Krogh A \& Lindhard J (1920) The relative value of fat and carbohydrate as sources of muscular energy. Biochemical Journal 14, 290-336.

Kryger AI (1998) Effects of Resistance Training on Skeletal Muscle and Function in the Oldest Old. PhD Thesis, University of Copenhagen.

Lavoisier AL (1777) Mémoire sur la combustion en général, pp. 592-600. Mémoire de l'Académie Royale des Sciences.

Mittendorfer B, Sidossis LS, Walser E, Chinkes DL \& Wolfe RR (1998) Regional acetate kinetics and oxidation in human volunteers. American Journal of Physiology 274, E978-E983.

Narici MV, Hoppeler H, Kayser B, Landoni L, Claassen H, Gavardi C, Conti M \& Cerretelli P (1996) Human quadriceps crosssectional area, torque and neural activation during 6 months strength training. Acta Physiologica Scandinavica 157, 175-186.

Narici MV, Roi GS, Landoni L, Minetti AE \& Cerretelli P (1989) Changes in force, cross-sectional area and neural activation during strength training and detraining of the human quadriceps. European Journal of Applied Physiology 59, 310-319.

Needham D (1971) Machina Carnis. London: Cambridge University Press.

Obenholzer F, Claassen H, Moesch H \& Howald H (1976) Ultrastrukturelle, biochemische und energetische analyse einer extremer dauerleistung (100 km lauf) (Microstructural, biochemical and energetic analysis of extreme continuous exercise (100 km run)). Schweizer Zeitschrift der Sportmedicin 24, 71-98.

O’Brien MJ, Viguie CA, Mazzeo RS \& Brooks GA (1993) Carbohydrate dependence during marathon running. Medicine and Science in Sports and Exercise 25, 1009-1017.

Odland LM, Heigenhauser GJF, Wong D, Hillidge-Horvat MG \& Spriet LL (1998) Effects of increased fat availability on fat- 
carbohydrate interaction during prolonged exercise in men. American Journal of Physiology 274, R894-R902.

Olsson AG, Eklund B, Kaijser L \& Carlson LA (1975) Extraction of endogenous plasma triglycerides by working human forearm muscle in the fasting state. Scandinavian Journal of Clinical and Laboratory Investigation 35, 231-236.

Pearce FJ \& Connett RJ (1980) Effect of lactate and palmitate on substrate utilisation of isolated rat soleus. American Journal of Physiology 238, C149-C159.

Pernow B \& Saltin B (editors) (1971) Muscle Metabolism during Exercise. Advances in Experimental Medicine and Biology, vol. 11. New York: Plenum Press.

Poole DC, Gaesser A, Hogan C, Knight DR \& Wagner PD (1992) Pulmonary and leg $\mathrm{VO}_{2}$ during submaximal exercise: implications for muscular efficiency. Journal of Applied Physiology 72, 805-810.

Price TB, Rothman DL \& Shulman RG (1999) NMR of glycogen in exercise. Proceedings of the Nutrition Society 58, 851-859.

Rådegran G (1997) Ultrasound doppler estimates of femoral artery blood flow during dynamic knee extensor exercise in humans. Journal of Applied Physiology 83, 1383-1388.

Rådegran G (1999) Limb and skeletal muscle blood flow measurements at rest and during exercise in human subjects. Proceedings of the Nutrition Society 58, 887-898.

Ray CA \& Dudley GA (1998) Muscle use during dynamic knee extension: Implication for perfusion and metabolism. Journal of Applied Physiology 85, 1194-1197.

Richardson RS, Poole DC, Knight DR, Kurdak SS, Hogan MC, Grassi B, Johnson EC, Kendrick KF, Erickson BK \& Wagner PD (1993) High muscle blood flow in man: is maximal $\mathrm{O}_{2}$ extraction compromised. Journal of Applied Physiology 75, 1911-1916.

Richardson RS \& Saltin B (1998) Human blood flow and metabolism studied in the isolated quadriceps muscle. Medicine and Science in Sports and Exercise 30, 28-33.

Richter EA, Kiens B, Galbo H \& Saltin B (editors) (1998) Skeletal Muscle Metabolism in Exercise and Diabetes. Advances in Experimental Medicine and Biology, vol. 441. New York: Plenum Press.

Rohen JW \& Yokochi C (1988) Color Atlas of Anatomy. A Photographic Study of the Human Body. New York: Igaku-Shion Medical Publishers Inc.

Saltin B \& Gollnick PD (1988) Fuel for muscular exercise. Role of carbohydrate. In Exercise, Nutrition and Energy Metabolism, pp. 45-71 [ES Horton and RL Terjung, editors]. New York: Macmillan Publishing Co.

Saltin B \& Kalsson J (1971) Muscle glycogen utilisation during work of different intensities. In Muscle Metabolism During Exercise. Advances in Experimental Medicine and Biology, vol. 11, pp. 289-299 [B Pernow and B Saltin, editors]. New York: Plenum Press.
Savard GK, Nielsen B, Laszczynska J, Larsen BE \& Saltin B (1988) Muscle blood flow is not reduced in humans during moderate exercise and heat stress. Journal of Applied Physiology 64, 649-657.

Seltzer WK, Angelini C, Dhariwal G, Ringel SP \& McCabe ERB (1989) Muscle glycerol kinase in Duchenne dystrophy and glycerol kinase deficiency. Muscle and Nerve 12, 307-313.

Sidossis LS, Coggan AR, Gastadelli A \& Wolfe RR (1995) A new correction factor for use in tracer estimations of plasma fatty acid oxidation. American Journal of Physiology 269, E649-E656.

Sjöström M, Fridén J \& Ekblom B (1982) Fine structural details of human muscle fibres after fibre type specific glycogen depletion. Histochemistry 76, 425-438.

Staron RS, Hikida RR, Murray TF \& Hagerman MT (1989) Lipid depletion and repletion in skeletal muscle following a marathon. Journal of Neurology Science 94, 29-40.

Toews C (1966) Evidence for the metabolism of glycerol by skeletal muscle and the presence of a muscle nicotinamide-adenine nucleotide phosphate-dependent glycerol dehydrogenase. Biochemical Journal 98, 27c-29c.

Turcotte LP, Richter EA \& Kiens B (1992) Increased plasma FFA uptake and oxidation during prolonged exercise in trained vs. untrained humans. American Journal of Physiology 262, E791-E799.

Van der Vusse GJ \& Reneman RS (1996) Lipid metabolism in muscle. In Handbook of Physiology. A Critical, Comprehensive Presentation of Physiological Knowledge and Concepts, pp. 952-994 [LB Rowell and JT Shepard, editors]. New York: Oxford University Press.

van Hall G (1999) Correction factors for ${ }^{13} \mathrm{C}$-labelled substrate oxidation at whole-body and muscle level. Proceedings of the Nutrition Society 58, 979-986.

Wahren J (1967) Quantitative aspects of blood flow and oxygen uptake in the human forearm during rhythmic exercise. Acta Physiologica Scandinavica 67, Suppl. 269, 5-88.

Wahren J, Alborg G \& Jorfeldt L (1971) Glucose metabolism during exercise in man. Journal of Clinical Investigation 50, 2715-2725.

Wendling PS, Peters SJ, Heigenhauser GJF \& Spriet LL (1996) Variability of triacylglycerol content in human skeletal muscle biopsy samples. Journal of Applied Physiology 81, 1150-1155.

Zierler KI (1961) Theory of the use of arteriovenous concentration differences for measuring metabolism in steady state and nonsteady state. Journal of Clinical Investigation 40, 2111-2125.

Zuntz N (1901) Ueber die bedeutung der vershiedenen nährstoffe als erzeuger der muskulkraft (An analysis of the value of various nutrients to generate muscle tone). Archiv für die Gesammte Physiologie 83, 557-571. 